\title{
Can depression be a menopause-associated risk?
}

\author{
Claudio N Soares ${ }^{1,2,3}$
}

\begin{abstract}
There is little doubt that women experience a heightened psychiatric morbidity compared to men. A growing body of evidence suggests that, for some women, the menopausal transition and early postmenopausal years may represent a period of vulnerability associated with an increased risk of experiencing symptoms of depression, or for the development of an episode of major depressive disorder. Recent research has begun to shed some light on potential mechanisms that influence this vulnerability. At the same time, a number of studies and clinical trials conducted over the past decade have provided important data regarding efficacy and safety of preventative measures and treatment strategies for midlife women; some of these studies have caused a shift in the current thinking of how menopausal symptoms should be appropriately managed.

Essentially, most women will progress from premenopausal into postmenopausal years without developing significant depressive symptoms. However, those with prior history of depression may face a re-emergence of depression during this transition while others may experience a first episode of depression in their lives. Here I provide an overview of what is known about risk factors for depression and the risk posed by the menopausal transition, its associated symptoms, and the underlying changes in the reproductive hormonal milieu, discussing the evidence for the occurrence of mood symptoms in midlife women and the challenges that face clinicians and health professionals who care for this population.
\end{abstract}

\section{Introduction}

Over the past few decades, growing epidemiological and clinical data support the notion that some, but not all, women may be at a heightened risk for psychiatric morbidity (for example, mood and anxiety symptoms, cognitive complaints) during periods in life that are associated with reproductive cycle events such as the postpartum period and the menopausal transition. These periods are not only marked by extreme hormone variations but may also be accompanied by the occurrence of significant life stressors and changes in personal, family, and professional responsibilities [1]. The complexity of the so-called female-specific 'windows of vulnerability' certainly poses a particular challenge to physicians and other professionals dedicated to women's health issues across the life span.

Among these female-specific 'windows of vulnerability', the menopausal transition constitutes a complex example: this transition is marked by progressive, dynamic changes in sex hormones and reproductive

\footnotetext{
Correspondence: csoares@mcmaster.ca

'Department of Psychiatry and Behavioural Neurosciences, McMaster

University, Hamilton, Ontario, Canada

Full list of author information is available at the end of the article
}

function. At the same time, these changes overlap with the aging process per se, and with modifications in metabolism, sexuality, lifestyle behaviors and overall health [2]. During this period in life, some individuals may seek medical treatment for a constellation of symptoms including vasomotor complaints (VMS; that is, hot flashes, night sweats), aches and stiff joints, trouble sleeping, and lack of energy. Others, on a more preventative approach, will inquire about different strategies (for example, hormonal, non-hormonal, 'natural' remedies) to promote a 'healthier' transition into postmenopausal years. Overall, diagnostic and therapeutic approaches to symptomatic women during the menopausal transition and postmenopausal years are, or should be, multifaceted and multidisciplinary in nature (Figure 1).

\section{Discussion}

For decades, the existence of a more causal, direct association between the menopausal transition and the emergence of depressive symptoms has been the subject of intense controversy; the question quite often posed by researchers and clinicians was whether the occurrence of menopause-associated depression was caused 


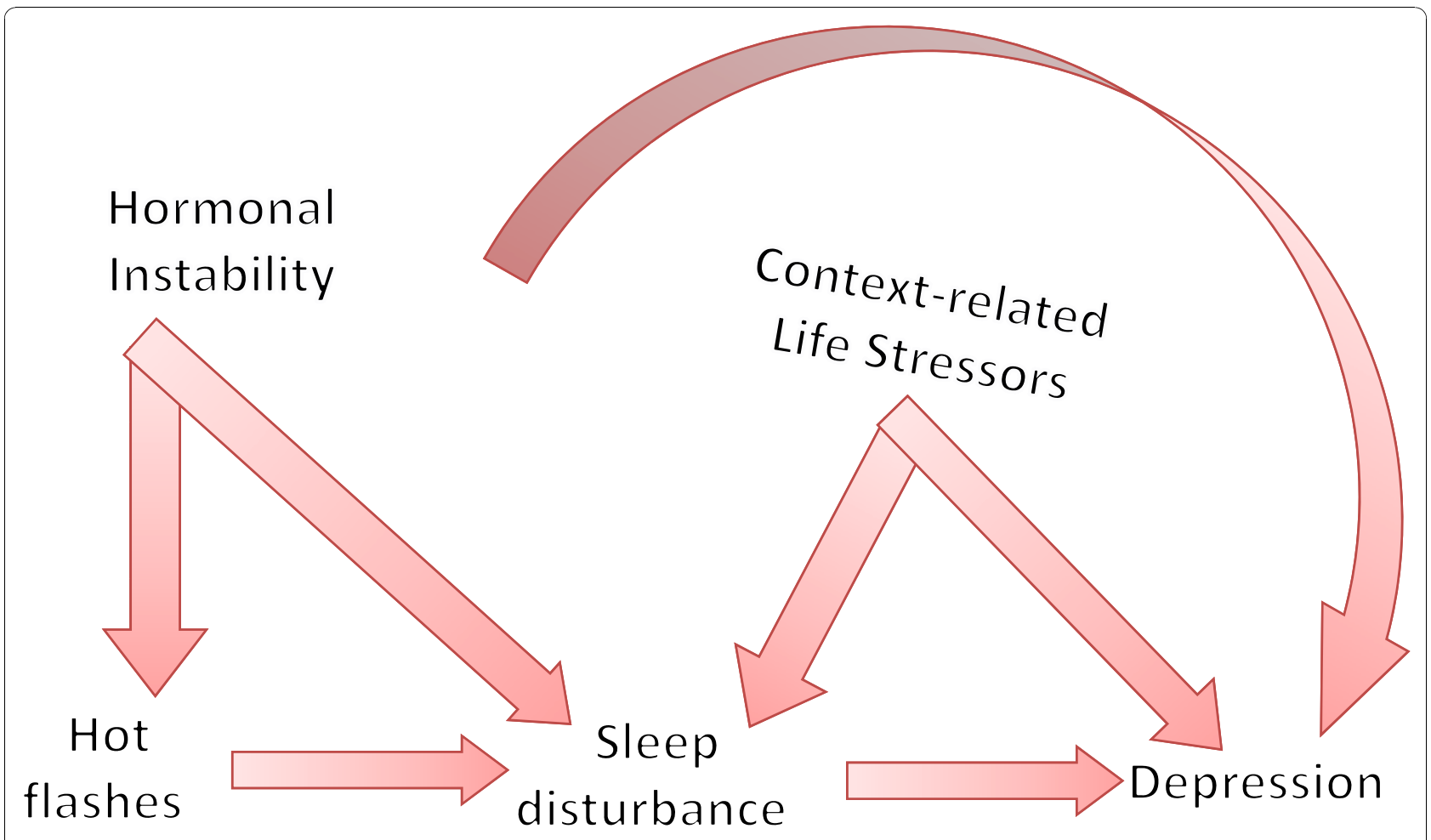

Figure 1 Exploring pathways for menopause-associated depression

primarily by stressful life events, psychological factors or by the impact of ovarian hormonal changes. This controversy is illustrated by the array of different theories and methodological approaches that has guided most of the research in this field. Some cross-sectional studies examining the relationship between menopause and depressive symptoms revealed no association [3-6], while others showed an increase in depression among women in the menopausal transition $[7,8]$. Among various theories, some have postulated that the occurrence of depression during this time in life could be in part modulated by the presence of sleep disruption and/or the occurrence of VMS. However, a recent study investigated this hypothesis by exploring the interactions between sleep, vasomotor symptoms and depression using objective and subjective sleep parameters in midlife women with and without depression [9]. Although depressed women reported poorer sleep quality and efficiency than non-depressed women, the two groups did not differ with respect to measurements of sleep interruption. Further, there was, no increased frequency of nocturnal vasomotor symptoms or awakenings observed among depressed women, refuting a direct link hypothesis.

Unlike the cross-sectional studies, most prospective studies [10-14] have systematically confirmed the menopausal transition as a period of heightened risk for development of depressive symptoms and/or depression. The Penn Ovarian Aging Study [12] showed an increased risk for depressive symptoms during the transition to menopause followed by a decrease in this risk in subsequent years (that is, in the postmenopausal period); the authors also suggested that depression and hormone-related symptoms could share some underlying mechanisms since history of severe PMS (premenstrual syndrome), emergence of hot flashes and sleep problems were independent predictors of depression in this population. Two long-term prospective studies followed women with no history of depression across the menopause transition to examine the risk for new onset of depression $[15,16]$. In both studies, a 6-8-year follow-up of premenopausal women $(n=460$ and $n=231$, respectively) revealed a significant increased risk (twofold to fourfold) for developing depression in women as they entered perimenopause compared to those who remained premenopausal. Moreover, greater variation of estradiol and follicle-stimulating hormone (FSH) levels over the follow-up period appear to be associated with higher depressive scores and diagnosis of MDD; an indicator that wide fluctuation in hormonal levels, rather than their absolute levels, may be a contributing factor to the emergence of depression in biologically vulnerable women. Other mediators of the risk for depression in this particular population include ethnicity (higher 
risk in African American, lower risk in Asian population), lower education, past history of postpartum blues or postpartum depression, cigarette smoking, stressful life events [10-16].

As highlighted above, epidemiologic evidence supports the 'critical timing' hypothesis for the occurrence of depression, most likely linked to periods of hormone instability rather then hormone deficiency. Interestingly, different areas of medicine exploring health-related outcomes in midlife and aging women seem to agree on the same notion of a 'critical timing window' being associated with the menopausal transition and the importance of proper timing for preventive or therapeutic strategies. For example, recent evidence from the Study of Women's Health Across the Nation (SWAN) showed changes in processing speed and verbal episodic memory in women during the menopausal transition, with memory performance returning to premenopausal levels in the postmenopausal years [17]. Changes in estrogen levels during the menopausal transition have also been associated with heightened risk for adverse cardiovascular events, including larger adventitial carotid artery diameters, changes in lipids, and increased blood pressure $[18,19]$.

Evidence from clinical trials supports the concept of a window of opportunity for hormonal treatment strategies in midlife women, not only for cardiovascular diseases but also, as further discussed, for menopauseassociated depression. An age-stratified analysis of the Women's Health Initiative (WHI) data revealed that several of the adverse events initially associated with menopausal hormone therapies (MHTs) in the entire study population were not evident in the subgroup of younger, postmenopausal women (between 50 and 59 years of age) or among those women who had recently transitioned into menopause. In fact, there seemed to be a cardioprotective effect of MHT (particularly estrogen based) when hormone therapies were administered to women within 10 years of the final menstrual period, possibly because of the fewer preexisting coronary conditions in this subgroup [20]. Further studies are needed to explore the risks and benefits of hormone therapies in younger, symptomatic women. Large-scale clinical studies such as Early versus Late Intervention Trial with Estrogen (ELITE; NCT00114517) and Kronos Early Estrogen Prevention Study (KEEPS; NCT00154180) [21] should be instrumental for the evaluation of "critical timing' for the use of hormone strategies from a cardiovascular and a cognitive perspective.

Antidepressant agents and psychotherapeutic treatments are widely accepted as first-line treatments for depression across the life span. Indeed, several trials have documented the efficacy of psychotropic medications for the alleviation of mood and other menopause- related symptoms in perimenopausal and postmenopausal women [22-26]. Despite that, preclinical and clinical evidence supports a possible window of opportunity for hormonal treatments to manage depressive episodes associated with the menopausal transition; after all, estrogen can, in many ways, modulate systems that are critical for mood and behavior regulation, particularly through pathways involving monoaminergic neurotransmission (serotonin (5-HT), norepinephrine (NE)) [27].

Estradiol (E2) administration decreases the activity of monoamine oxidases (MAO-A and MAO-B), which are enzymes involved in 5-HT degradation; E2 administration also increases both isoforms of tryptophan hydroxylase $(\mathrm{TPH})$, the rate-limiting enzyme of serotonin synthesis, resulting in an overall increase in 5-HT synthesis and availability. Furthermore, by downregulating $5 \mathrm{HT}_{1 \mathrm{a}}$ autoreceptors and upregulating $5 \mathrm{HT}_{2 \mathrm{a}}$ receptors, E2 increases the amount of serotonin found in the synapse and increases the amount available for postsynaptic transmission. Similarly, estrogens increase NE availability by decreasing expression of MAOs and increasing the activity of tyrosine hydroxylase, the ratelimiting enzyme in the synthetic pathway of catecholamine [28].

Estrogen-based therapies have shown superior antidepressant effects compared to placebo when administered to perimenopausal women $[29,30]$. The antidepressant effects of estrogen were observed even in the absence of concomitant vasomotor symptoms [30]. Older, postmenopausal women, however, showed little or no response to estrogen therapy for the alleviation of depressive symptoms [31]. Taken together, these observations suggest that estrogen's antidepressant effect may have a 'critical window' or optimal timing, possibly during the MT and early postmenopausal years; moreover, the potential benefits of E2 therapy for the improvement of mood symptoms may occur independent from changes/improvement of vasomotor symptoms.

As symptomatic midlife women may endorse a wide variety of physical and emotional complaints, physicians and other health professionals have the challenging task to disentangle the biological and psychosocial aspects that could be primarily attributed to (a) the aging process per se; (b) the menopausal transition; (c) the emergence of new onset/recurrent depression.

\section{Conclusions}

Robust epidemiologic evidence supports the existence of a 'window of vulnerability' for the occurrence of depression (new onset or recurrent) during the menopausal transition and early postmenopausal years. Similar to that observed in other periods in life, antidepressants and psychotherapies continue to be the treatments of choice for depression occurring in midlife women. 
Nonetheless, accumulated preclinical and clinical data support the benefits of estrogen-based therapies to improve mood and other menopause-related symptoms during this critical window. As such, estrogen should be considered part of the treatment armamentarium for depression, along with other well established benefits (for example, for vasomotor, sexual and other menopause-related complaints) [32]. Lastly, the use of specific screening and diagnostic tools for depression in women [33] should help physicians and health professionals to improve early detection and clinical management. Ultimately, treatment strategies should be tailored and incorporate all the resources available to reduce the significant burden and functional impairment associated with depression in women undergoing menopause.

\section{Author details \\ 'Department of Psychiatry and Behavioural Neurosciences, McMaster University, Hamilton, Ontario, Canada. ${ }^{2}$ Department of Obstetrics and Gynecology, McMaster University, Hamilton, Ontario, Canada. ${ }^{3}$ Mood Disorders Division, McMaster University, Hamilton, Ontario, Canada.}

\section{Competing interests}

CNS has received research support from Allergen National Centre of Excellence, the Canadian Institutes of Health Research, the NARSAD Brain and Behavior Research Foundation, Eli Lilly, Pfizer, AstraZeneca, and Hamilton Community Foundation. He has received honoraria as a consultant and/or speaker for Wyeth, Pfizer, AstraZeneca, Eli Lilly, Lundbeck, and Bayer Schering Pharmaceuticals.

Received: 9 November 2010 Accepted: 1 December 2010 Published: 1 December 2010

\section{References}

1. Soares CN, Zitek B: Reproductive hormone sensitivity and risk for depression across the female life cycle: a continuum of vulnerability? J Psychiatry Neurosci 2008, 33:331-343.

2. Santoro N, Neal-Perry G: Normal aging and the menopausal transition: what to expect. In The Menopausal Transition: Interface Between Psychiatry and Gynecology. Edited by: Soares CN, Warren M. Basel, Switzerland: Karger; 2009:1-17.

3. Dennerstein L, Smith AM, Morse C: Psychological well-being, mid-life and the menopause. Maturitas 1994, 20:1-11.

4. McKinlay JB, McKinlay SM, Brambilla D: The relative contribution of endocrine changes and social circumstances to depression in mid-aged women. J Health Social Behav 1987, 25:345-363.

5. Woods NF, Mitchell ES: Pathways to depressed mood for midlife women: observations from the Seattle Midlife Women's Health Study. Res Nurs Health 1997, 20:119-129.

6. Slaven $L$, Lee C: Mood and symptom reporting among middle-aged women: the relationship between menopausal status, hormone replacement therapy, and exercise participation. Health Psychol 1997, 16:203-208.

7. Avis NE, Crawford S, Stellato R, Longcope C: Longitudinal study of hormone levels and depression among women transitioning through menopause. Climacteric 2001, 3:243-249.

8. Bromberger JT, Meyer PM, Kravitz HM, Sommer B, Cordal A, Powell L, Ganz PA, Sutton-Tyrrell K: Psychologic distress and natural menopause: a multiethnic community study. Am J Public Health 2001, 91:1435-1442.

9. Joffe H, Soares CN, Thurston RC, White DP, Cohen LS, Hall JE: Depression is associated with worse objectively and subjectively measured sleep, but not more frequent awakenings, in women with vasomotor symptoms. Menopause 2009, 16:671-679.
10. Avis NE, Brambilla D, McKinlay SM, Vass K: A longitudinal analysis of the association between menopause and depression. Results from the Massachusetts Women's Health Study. Ann Epidemiol 1994, 4:214-220.

11. Bromberger JT, Matthews KA, Schott LL, Brockwell S, Avis NE, Kravitz HM, Everson-Rose SA, Gold EB, Sowers M, Randolph JF Jr: Depressive symptoms during the menopausal transition: the Study of Women's Health Across the Nation (SWAN). J Affect Disord 2007, 103:267-272.

12. Freeman EW, Sammel MD, Liu L, Gracia CR, Nelson DB, Hollander L: Hormones and menopausal status as predictors of depression in women in transition to menopause. Arch Gen Psychiatry 2004, 61:62-70.

13. Maartens LW, Knottnerus JA, Pop VJ: Menopausal transition and increased depressive symptomatology: a community based prospective study. Maturitas 2002, 42:195-200.

14. Woods NF, Smith-DiJulio K, Percival DB, Tao EY, Mariella A, Mitchell S: Depressed mood during the menopausal transition and early postmenopause: observations from the Seattle Midlife Women's Health Study. Menopause 2008, 15:223-232.

15. Cohen LS, Soares CN, Vitonis AF, Otto MW, Harlow BL: Risk for new onset of depression during the menopausal transition: the Harvard study of moods and cycles. Arch Gen Psychiatry 2006, 63:385-390.

16. Freeman EW, Sammel MD, Lin H, Nelson DB: Associations of hormones and menopausal status with depressed mood in women with no history of depression. Arch Gen Psychiatry 2006, 63:375-382.

17. Greendale GA, Huang MH, Wight RG, Seeman T, Luetters C, Avis NE, Johnston J, Karlamangla AS: Effects of the menopause transition and hormone use on cognitive performance in midlife women. Neurology 2009, 72:1850-1857.

18. Wildman RP, Colvin AB, Powell LH, Matthews KA, Everson-Rose SA, Hollenberg S, Johnston JM, Sutton-Tyrrell K: Associations of endogenous sex hormones with the vasculature in menopausal women: the Study of Women's Health Across the Nation (SWAN). Menopause 2008, 15:414-421.

19. Matthews KA, Crawford SL, Chae CU, Everson-Rose SA, Sowers MF, Sternfeld B, Sutton-Tyrrell K: Are changes in cardiovascular disease risk factors in midlife women due to chronological aging or to the menopausal transition? J Am Coll Cardiol 2009, 54:2366-2373.

20. Rossouw JE, Prentice RL, Manson JE, Wu L, Barad D, Barnabei VM, Ko M, LaCroix AZ, Margolis KL, Stefanick ML: Postmenopausal hormone therapy and risk of cardiovascular disease by age and years since menopause. JAMA 2007, 297:1465-1477.

21. Harman SM, Brinton EA, Cedars M, Lobo R, Manson JE, Merriam GR, Miller VM, Naftolin F, Santoro N: KEEPS: The Kronos Early Estrogen Prevention Study. Climacteric 2005, 8:3-12.

22. Soares CN, Arsenio H, Joffe H, Bankier B, Cassano P, Petrillo LF, Cohen LS: Escitalopram versus ethinyl estradiol and norethindrone acetate for symptomatic peri- and postmenopausal women: impact on depression, vasomotor symptoms, sleep, and quality of life. Menopause 2006, 13:780-786.

23. Joffe H, Soares CN, Petrillo LF, Viguera AC, Somley BL, Koch JK, Cohen LS: Treatment of depression and menopause-related symptoms with the serotonin-norepinephrine reuptake inhibitor duloxetine. J Clin Psychiatry 2007, 68:943-950.

24. Soares CN, Thase ME, Clayton A, Guico-Pabia CJ, Focht K, Jiang Q, Kornstein SG, Ninan P, Kane CP, Cohen LS: Desvenlafaxine and escitalopram for the treatment of postmenopausal women with major depressive disorder. Menopause 2010, 17:700-711.

25. Kornstein SG, Jiang Q, Reddy S, Musgnung JJ, Guico-Pabia CJ: Short-term efficacy and safety of desvenlafaxine in a randomized, placebocontrolled study of perimenopausal and postmenopausal women with major depressive disorder. J Clin Psychiatry 2010, 71:1088-1096.

26. Soares CN, Frey BN, Haber E, Steiner M: A pilot, 8-week, placebo lead-in trial of quetiapine extended release for depression in midlife women: impact on mood and menopause-related symptoms. J Clin Psychopharmacol 2010, 30:612-615.

27. Stahl SM: Basic psychopharmacology of antidepressants, part 2: Estrogen as an adjunct to antidepressant treatment. J Clin Psychiatry 1998, 59(Suppl 4):15-24.

28. Lokuge S, Frey BN, Foster JA, Soares CN, Steiner M: The rapid effects of estrogen: a mini-review. Behav Pharmacol 2010, 21:465-72.

29. Soares CN, Almeida OP, Joffe H, Cohen LS: Efficacy of estradiol for the treatment of depressive disorders in perimenopausal women: a double- 
blind, randomized, placebo controlled trial. Arch Gen Psychiatry 2001, 58:529-534.

30. Schmidt PJ, Nieman L, Danaceau MA, Tobin MB, Roca CA, Murphy JH, Rubinow DR: Estrogen replacement in perimenopause-related depression: a preliminary report. Am J Obstet Gynecol 2000, 183:414-420.

31. Morrison MF, Kallan MJ, Ten Have T, Katz I, Tweedy K, Battistini M: Lack of efficacy of estradiol for depression in postmenopausal women: a randomized, controlled trial. Biol Psychiatry 2004, 55:406-412.

32. Studd J: Ten reasons to be happy about hormone replacement therapy: a guide for patients. Menopause Int 2010, 16:44-46.

33. Martini J, Wittchen HU, Soares CN, Rieder A, Steiner M: New womenspecific diagnostic modules: the Composite International Diagnostic Interview for Women (CIDI-VENUS). Arch Womens Ment Health 2009, 12:281-289.

\section{Pre-publication history}

The pre-publication history for this paper can be accessed here: http://www.biomedcentral.com/1741-7015/8/79/prepub

doi:10.1186/1741-7015-8-79

Cite this article as: Soares: Can depression be a menopause-associated risk? BMC Medicine 2010 8:79.

\section{Submit your next manuscript to BioMed Central} and take full advantage of:

- Convenient online submission

- Thorough peer review

- No space constraints or color figure charges

- Immediate publication on acceptance

- Inclusion in PubMed, CAS, Scopus and Google Scholar

- Research which is freely available for redistribution

Submit your manuscript at www.biomedcentral.com/submit
C Biomed Central 